\title{
OLIGONUCLEOTIDE PRIMERS FOR THE DETECTION OF BIOLUMINESCENT DINOFLAGELLATES REVEAL NOVEL LUCIFERASE SEQUENCES AND INFORMATION ON THE MOLEGULAR EVOLUTION OF THIS GENE
}

\author{
Andrea Baker \\ School of Ocean and Earth Sciences, University of Southampton, National Oceanography Centre, European Way, \\ Southampton SO14 3ZH, UK
}

Ian Robbins, Mark A. Moline

Biological Sciences Department, Center for Marine and Coastal Sciences, California Polytechnic State University, San Luis Obispo, California 93407, USA

and Maria Debora Iglesias-Rodríguez

School of Ocean and Earth Sciences, University of Southampton, National Oceanography Centre, European Way, Southampton SO14 3ZH, UK

Bioluminescence is reported in members of 18 dinoflagellate genera. Species of dinoflagellates are known to have different bioluminescent signatures, making it difficult to assess the presence of particular species in the water column using optical tools, particularly when bioluminescent populations are in nonbloom conditions. A "universal" oligonucleotide primer set, along with species and genus-specific primers specific to the luciferase gene were developed for the detection of bioluminescent dinoflagellates. These primers amplified luciferase sequences from bioluminescent dinoflagellate cultures and from environmental samples containing bioluminescent dinoflagellate populations. Novel luciferase sequences were obtained for strains of Alexandrium cf. catenella (Whedon et Kof.) Balech and Alexandrium fundyense Balech, and also from a strain of Gonyaulax spinifera (Clap. et Whitting) Diesing, which produces bioluminescence undetectable to the naked eye. The phylogeny of partial luciferase sequences revealed five significant clades of the dinoflagellate luciferase gene, suggesting divergence among some species and providing clues on their molecular evolution. We propose that the primers developed in this study will allow further detection of low-light-emitting bioluminescent dinoflagellate species and will have applications as robust indicators of dinoflagellate bioluminescence in natural water samples.

Key index words: bioluminescence; CODEHOP PCR; dinoflagellates; luciferase; phylogeny

Abbreviations: CODEHOP, consensus-degenerate hybrid oligonucleotide primer
The class Dinophyceae comprises a highly significant ecological group consisting of 117 genera, with 1,555 free-living species (Gomez 2005). This group performs numerous globally important functions, including primary production, grazing, toxin production, symbiosis, and bioluminescence (reviewed by Hackett et al. 2004). Eighteen of these genera have been documented to possess members that are capable of bioluminescence (reviewed by Poupin et al. 1999).

The bioluminescent system in dinoflagellates is unique in that the bioluminescence originates from specific cellular organelles that exist as outpockets from the cell vacuole. These organelles, termed scintillons, are approximately $0.5 \mu \mathrm{m}$ in diameter and are the reaction centers of bioluminescence (DeSa and Hastings 1968). The scintillons contain luciferase, a luciferin substrate, and, occasionally, also a luciferin-binding protein (Knaust et al. 1998, Akimoto et al. 2004). Mechanical stimulation of dinoflagellate cells, often induced by grazers, creates an action potential across the vacuole membrane and the scintillons, creating a shift in $\mathrm{pH}$ in the scintillons and causing the luciferase to take on its active conformation (reviewed by Hastings 1996). This reaction of the luciferin substrate and luciferase brings about a brief flash of light of $\sim 100 \mathrm{~ms}$, between 474 and $476 \mathrm{~nm}$ (Fogel and Hastings 1972, Sweeney 1987), and is controlled by circadian rhythms, only occurring during the night (Hastings 1989, Fritz et al. 1990, Knaust et al. 1998).

Numerous theories attempt to explain the ecological function of dinoflagellate bioluminescence (Burkenroad 1943, Esaias and Curl 1972). One of the more widely accepted hypotheses is the "burglar alarm" hypothesis, which proposes that when grazers stimulate bioluminescence in dinoflagellates, it 
essentially serves as a "beacon" to the predators of dinoflagellate grazers, enticing them into the area. The net effect of this phenomenon is that the grazers of the dinoflagellates are attacked, increasing the dinoflagellate survival rate (Burkenroad 1943, Abrahams and Townsend 1993, Fleisher and Case 1995). This effect has been observed in several experimental situations, and, if it indeed occurs in the natural environment, these bioluminescent dinoflagellates have the potential to restructure marine food webs, altering the microbial community and affecting food web dynamics.

There are few reports on the origin and evolution of the luciferase bioluminescent system in the dinoflagellates. Bioluminescence has been determined to be conserved in a range of different species, including Noctiluca scintillans (Eckert and Reynolds 1967), Lingulodinium polyedrum (DeSa and Hastings 1968), and species of Pyrocystis (Schmitter et al. 1975). Additionally, seven dinoflagellate luciferase genes from members of the Gonyaulacales and Pyrocystales have been fully sequenced to date. These genes share similarities in their structure and organization and also share considerable sequence homology (Liu et al. 2004). The dinoflagellate luciferase sequences form a unique clade and are therefore thought to have evolved separately from other luciferase systems. The typical luciferase structure comprises a short $\mathrm{N}$-terminal region, which is preceded by three conserved catalytically active domains that are highly similar across the dinoflagellate group (Okamoto et al. 2001, Liu et al. 2004). Pyrocystis lunula is the only dinoflagellate luciferase, reported to date, to have an intron in one of its genes (Okamoto et al. 2001). Other significant features within the dinoflagellate luciferase group include differences in untranslated region sequences and also the length of these regions. $P$. lunula also has an increased rate of silent mutations across all three of the repeat domains, a pattern not observed in L. polyedrum (Okamoto et al. 2001). The sequence conservation between the seven dinoflagellates, within the catalytically active domains and also the N-terminal region, has led to speculation that the bioluminescent dinoflagellates have descended from a common ancestor. More specifically, it has been hypothesized that the dinoflagellate L. polyedrum diverged from other dinoflagellate species earlier on in its evolutionary history (Liu et al. 2004). Many questions regarding dinoflagellate bioluminescence remain unanswered, including the acquisition of bioluminescence; what it evolved from; why bioluminescence persisted in certain species and not others, with some members of a genus, such as species of Alexandrium, showing bioluminescence and some not; and also how bioluminescence developed over evolutionary time. By studying the luciferase gene, we will further our understanding of the ecological and evolutionary advantage of bioluminescence.
This study presents universal luciferase PCR primers for the detection of bioluminescent dinoflagellates and also a suite of genus/species-specific luciferase primers. This methodology was possible due to the conserved nature of the dinoflagellate luciferase gene sequence (Liu et al. 2004) and the conserved functionality of the luciferase system in a range of different strains. Although most of the strains identified as bioluminescent are detectable to the naked eye, certain strains produce low levels of bioluminescence or require high cell densities for detectable bioluminescence. Consequently, PCRbased primers capable of detecting bioluminescent strains, at low numbers, or during the day when the circadian rhythms "switch off" bioluminescence, represent promising tools for ecological studies. We present novel luciferase sequences and discuss the molecular evolution of dinoflagellate luciferase using ecologically relevant species.

\section{MATERIALS AND METHODS}

Dinoflagellate strain cultures. Dinoflagellate cultures were obtained from the Provasoli-Guillard National Center for Culture of Marine Phytoplankton (CCMP; West Boothbay Harbor, ME, USA), the Culture Collection of Algae and Protozoa (CCAP; Oban, UK), Plymouth Culture Collection of Marine Algae (PLY; Plymouth, UK), and from members of the molecular laboratory at the National Oceanography Centre (Southampton, UK) (see Table S1 in the supplementary material). Strains were grown in $200 \mathrm{~mL}$ batch cultures in $\mathrm{f} / 2$ medium, minus silicate (Guillard and Ryther 1962), in $250 \mathrm{~mL}$ conical flasks at $19 \pm 1^{\circ} \mathrm{C}$ (with the exception of Ceratocorys horrida $\mathrm{F}$. Stein, which was incubated at $25^{\circ} \mathrm{C}$ ) on a 12:12 light:dark (L:D) cycle at $100 \mu \mathrm{mol} \cdot \mathrm{m}^{-2} \cdot \mathrm{s}^{-1}$ without shaking.

Environmental sample collection. Seawater samples from San Luis Obispo Bay (35.1011 N, 120.4428 W), California, USA, were collected autonomously from the California Polytechnic State University pier using $5 \mathrm{~L}$ Niskin bottles mounted with a conductivity-temperature-depth seabird SBE-37 SIP MicroCAT profiler (Sea-bird Electronics Inc., Bellevue, WA, USA) and a bioluminescence bathyphotometer (Herren et al. 2005) (Fig. 1, Table 1). A $500 \mathrm{~mL}$ seawater sample was vacuum filtered through $25 \mathrm{~mm} \mathrm{GF} / \mathrm{F}$ filters (Whatman, Maidstone, UK) and was stored at $-20^{\circ} \mathrm{C}$ until DNA extraction. The sample from the English Channel was collected at $49.5472 \mathrm{~N}$, $4.3966 \mathrm{~W}$, using a Niskin bottle mounted on a wire (Table 1). Samples were also filtered through $25 \mathrm{~mm} \mathrm{GF/F} \mathrm{filters} \mathrm{and}$ stored at $-20^{\circ} \mathrm{C}$; however, bioluminescence measurements were not taken at this location.

Dinoflagellate DNA extraction. Dinoflagellate cultures were concentrated by centrifugation in $50 \mathrm{~mL}$ volumes at $4,250 \mathrm{~g}$ for $5 \mathrm{~min}$. The pelleted cells, from $50 \mathrm{~mL}$ of culture, were resuspended in $200 \mu \mathrm{L}$ cetyl-trimethylammonium bromide (CTAB) buffer $(2 \%$ [w/v] CTAB, $2 \%$ polyvinylpyrrolidone [PVP], $0.5 \% \beta$-mercaptoethanol, $1.4 \mathrm{M} \mathrm{NaCl}, 20 \mathrm{mM}$ EDTA, $100 \mathrm{mM}$ Tris-Cl, $\mathrm{pH} 8$ ) prewarmed to $60^{\circ} \mathrm{C}$ according to Doyle and Doyle (1990). Cells were vortexed for $1 \mathrm{~min}$, until the mixture was even and homogenous, and then a further $800 \mu \mathrm{L}$ of CTAB buffer was added, after which the mixture was vortexed for a further minute. Samples were incubated at $60^{\circ} \mathrm{C}$ for $30 \mathrm{~min}$ with regular gentle mixing. Proteins were removed by extraction in an equal volume of chloroform: isoamylalcohol (24:1), and this step was followed by DNA precipitation in $0.6 \times$ volume cold isopropanol and 


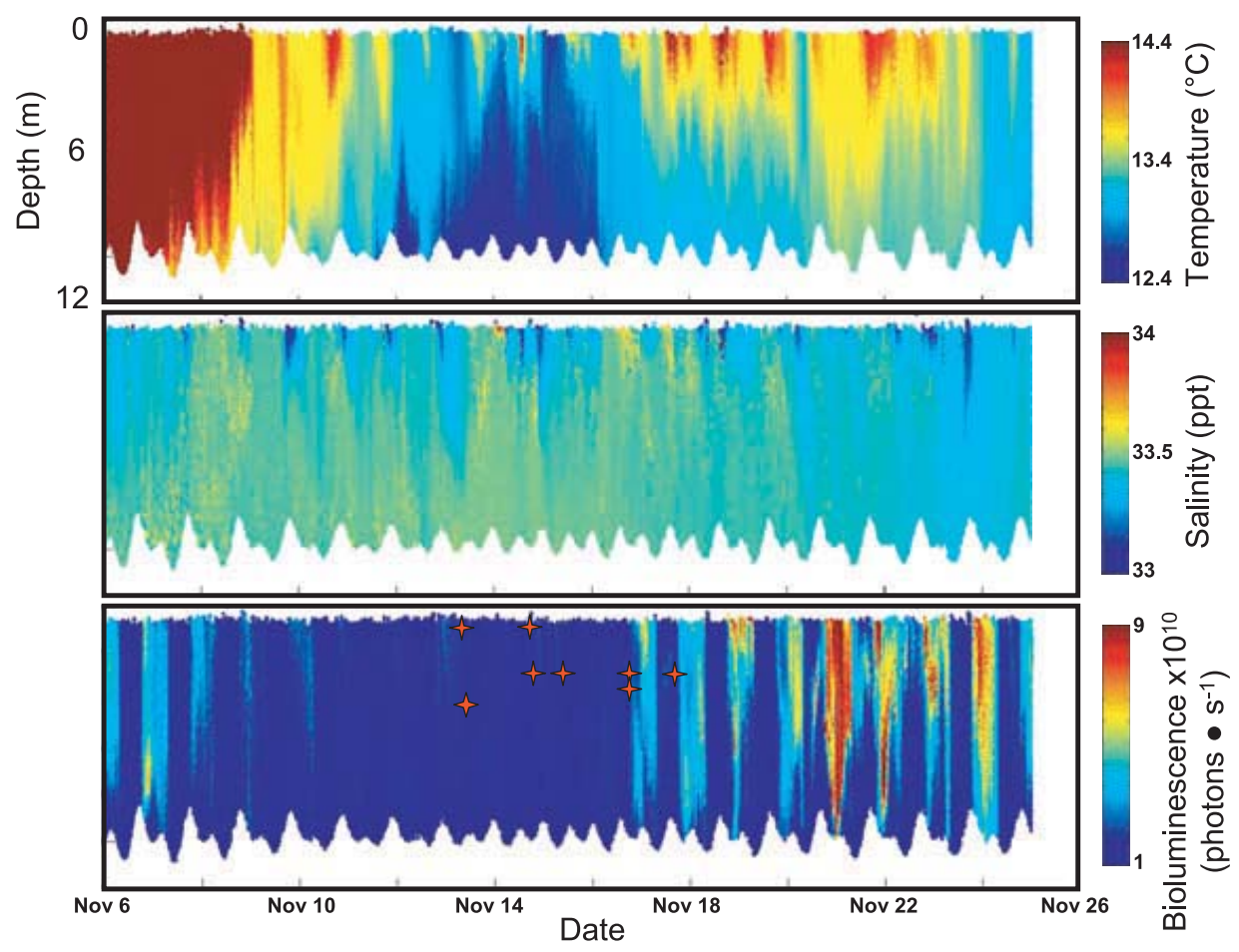

FIG. 1. Time series of the depth distribution of temperature (top), salinity (middle), and bioluminescence potential (bottom) from San Luis Obispo Bay, California, USA. Red stars in the lower panel indicate the depth and time of sampling of environmental samples (Table 1). Dynamics show that sampling occurred during a transition from a cold-water intrusion onto the shelf to a water mass subjected to stratification by local heating. Bioluminescence intensified during this warmer period.

$0.1 \times$ volume $7.5 \mathrm{M}$ ammonium acetate at $-20^{\circ} \mathrm{C}$ for at least $1 \mathrm{~h}$. DNA was recovered by centrifugation at $26,000 \mathrm{~g}$ for 15 min in a microcentrifuge. The supernatant was removed and discarded, and the pellet was washed in $500 \mu \mathrm{L}$ cold $76 \%$ (v/v) ethanol containing $10 \mathrm{mM}$ ammonium acetate. The supernatant was again discarded, and the DNA pellet was air-dried and resuspended in $30 \mu \mathrm{L}$ TE $(10 \mathrm{mM}$ Tris-Cl; 1 mM EDTA).

Environmental DNA extraction. DNA was extracted from the environmental filters according to Goddard et al. (2005). Extracted DNA was gel purified on a $1 \%(\mathrm{w} / \mathrm{v})$ agarose gel in $1 \times$ TAE $(0.04 \mathrm{M}$ Tris-Cl, $0.04 \mathrm{M}$ acetic acid, $0.001 \mathrm{M}$ EDTA) containing $1 \mathrm{mg} \cdot \mathrm{mL}^{-1}$ ethidium bromide. Gels were viewed by UV documentation (Bio-Rad, Hercules, CA, USA); DNA was excised from the gel using a sterile scalpel and was subsequently purified from the agarose using the Wizard SV gel purification kit (Promega UK, Southampton, UK).

Primer design. Universal primers were designed using the consensus-degenerate hybrid oligonucleotide primer (CODEHOP) strategy (Rose et al. 1998). Dinoflagellate luciferase sequences were retrieved from GenBank and aligned using BlockMaker (http://blocks.fhcrc.org/). Optimal blocks containing conserved amino acids were identified, and the CODEHOP software predicted PCR primers from these blocks. The primers were checked for any other homology with other organisms using BLAST (Basic Local Alignment Search Tool) within the NCBI (National Center for Biotechnology Information) database (http://www.//ncbi.nlm.nih.gov/BLAST) (Altschul et al. 1990) and also to verify that they would not amplify duplicate sequences within a single organism. Finally, OligoAnalyzer 3.0 (Integrated DNA Technologies, Coralville, IA, USA) was used to ensure the primers were compatible and optimal for PCR amplification. The final primer sets, LcfCHF3 and LcfCHR4 (Table 2), corresponded to amino acids QVAR-
LAAW and CKGFDYGNKT, which are located at the end of the $\mathrm{N}$-terminal region and the beginning of the first domain, respectively (Fig. 2). Based on the alignment of luciferase sequences, regions unique to the different dinoflagellate genera or species were used to design specific primers (Table 2).

PCR reaction. PCR primer pairs were optimized and tested on DNA from clonal cultures of 27 dinoflagellate strains (Table S1) and also from environmental samples (Table 1). Reactions were carried out in $25 \mu \mathrm{L}$ volumes containing $0.0625 \mathrm{mM}$ each dNTP, 20 pmol each primer (with the exception of LcfCHF3, LcfCHR4, PYROF2, and PYROR2, where 30 pmol was used), $1 \times$ PCR reaction buffer (containing $1.5 \mathrm{mM} \mathrm{MgCl} \mathrm{Mg}_{2}$ ), $0.5 \mathrm{U}$ Gotaq polymerase (Promega UK), and approximately $100 \mathrm{ng}$ template. All PCR reactions commenced with an initial $5 \mathrm{~min}$ at $95^{\circ} \mathrm{C}$, which was followed by 35 cycles of $45 \mathrm{~s}$ at $95^{\circ} \mathrm{C}, 30 \mathrm{~s}$ at $62^{\circ} \mathrm{C}$, and $30 \mathrm{~s}$ at $68^{\circ} \mathrm{C}$ for LcfCHF3/R4; 32 cycles of $45 \mathrm{~s}$ at $95^{\circ} \mathrm{C}, 30 \mathrm{~s}$ at $61^{\circ} \mathrm{C}$, and $15 \mathrm{~s}$ at $68^{\circ} \mathrm{C}$ for AlexF1/R1; 30 cycles of $45 \mathrm{~s}$ at $95^{\circ} \mathrm{C}, 30 \mathrm{~s}$ at $69^{\circ} \mathrm{C}$, and $20 \mathrm{~s}$ at $72^{\circ} \mathrm{C}$ for LpolyF1/R1; 30 cycles of $45 \mathrm{~s}$ at $95^{\circ} \mathrm{C}, 30 \mathrm{~s}$ at $58^{\circ} \mathrm{C}$, and $20 \mathrm{~s}$ at $68^{\circ} \mathrm{C}$ for PyroF2/R2; and 30 cycles of $45 \mathrm{~s}$ at $95^{\circ} \mathrm{C}$, $30 \mathrm{~s}$ at $58^{\circ} \mathrm{C}$, and $30 \mathrm{~s}$ at $68^{\circ} \mathrm{C}$ for PreticF1/R1. Reactions were followed by a final extension step for $10 \mathrm{~min}$ at the respective temperature. Thereafter, $20 \mu \mathrm{L}$ of the PCR reaction mixtures was electrophoresed on a $1 \%(\mathrm{w} / \mathrm{v})$ agarose gel in $1 \times \mathrm{TAE}$ containing $1 \mathrm{mg} \cdot \mathrm{mL}^{-1}$ ethidium bromide. Gels were viewed by UV documentation; PCR products were excised from the gel using a sterile scalpel and were subsequently purified from the agarose using the Wizard SV gel purification kit (Promega UK).

Cloning and sequencing. PCR products from single strain cultures were sequenced directly from the PCR product by Geneservice Ltd. (Cambridge, UK). PCR products generated from environmental samples were gel purified and then cloned 


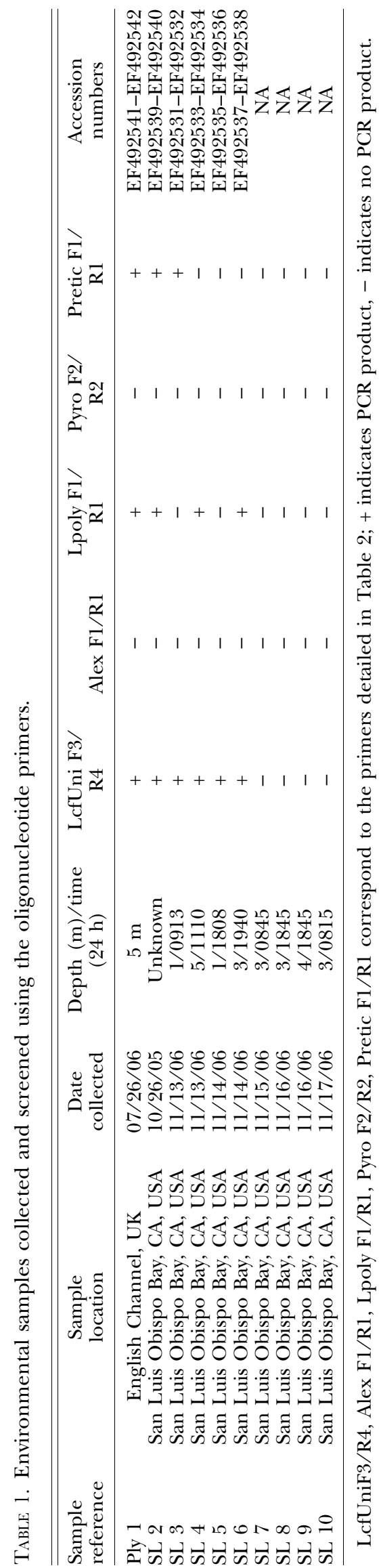

into the pCR 2.1 TA cloning vector (Invitrogen Ltd., Paisley, UK), according to the manufacturer's instructions. Inserts were verified by M13 PCR screening, and positive clones were sequenced by Geneservice Ltd.

Sequence data were automatically collated, analyzed using Chromas 2.31 (Technelysium Pty. Ltd., Tewantin, Australia) software, and subsequently manually verified. Similarities of amplified to published luciferase sequences were determined using BLAST (Altschul et al. 1990) within the NCBI database. Searches were undertaken at the nucleotide level (BLASTn) to identify similar sequences and to verify that the correct product had been generated by PCR.

Phylogenetic analysis. Multiple sequences were aligned using ClustalW (Thompson et al. 1994), and phylogenetic analysis of the alignments was undertaken using Phylip version 3.66 (Felsenstein 1993). Trees were constructed based on the distances obtained using the neighbor-joining method. The reliability of the trees was tested by bootstrapping (100 replicates) using neighbor-joining and parsimony. Trees were viewed using TreeView version 1.6.6 (Page 1996).

\section{RESULTS}

Light emission by dinoflagellate strains. Of the 27 strains tested, 18 dinoflagellate strains were positive for bioluminescence, induced by shaking of the cultures (Table S1). Among these strains, 17 could be discriminated visually; however, one strain, G. spinifera CCMP 409, was dimly bioluminescent, being only detected by a sensitive luminescence spectrometer (BMG LabTech FLUOstar Optima, Aylesbury, UK) (data not shown).

Development of a suite of oligonucleotide primers specific to bioluminescent dinoflagellates. The CODEHOP software identified block motifs within the luciferase amino acid sequence, which allowed the development of primer pairs for the luciferase gene family. The two primers selected corresponded to amino acids QVARLRAAW and CKGFDYGNKT (Fig. 2), the primers comprising a $3^{\prime}$ degenerate core and a longer $5^{\prime}$ nondegenerate clamp, according to the CODEHOP protocol. This primer set was successful in yielding PCR products of approximately $480 \mathrm{bp}$ from 18 strains out of 27 tested, with these 18 being the positively bioluminescent strains (Table S1). The other dinoflagellate species/genus-specific primer pairs were verified against the 27 dinoflagellate strains and were all determined to be specific to the groups for which they were designed (Table S1). The PCR products amplified from the different primer sets were all sequenced to confirm that the correct product had been amplified and to also allow further genetic analysis.

Primer pairs were tested on the DNA extracted from the environmental samples from California, where bioluminescence was observed in the water column (Fig. 1), and the English Channel, which was not tested for bioluminescence, to screen for bioluminescent dinoflagellates. Six of the 10 samples tested yielded PCR products using the universal luciferase primer pair. Of these six, samples Ply1 and SL2 produced PCR products using both the 
TABLE 2. Dinoflagellate luciferase PCR primers designed in this study.

\begin{tabular}{|c|c|c|c|}
\hline Primer & Sequence $\left(5^{\prime}-3^{\prime}\right)$ & Target & Product size $(b p)$ \\
\hline LcfUniCHF3 & TCCAGGTTGCACGGCTTCGAGCNGCNTGGC & "'Universal”' & $500-550$ \\
\hline LcfUniCHR4 & GGGTCTTGTCGCCGTAGTCAAANCCYTTRCA & & \\
\hline AlexF1 & CATTGATGCCAGCGTCGC & Alexandrium species & 276 \\
\hline AlexR1 & GAAGGTGCCTTCACCGAGATG & & \\
\hline PyroF2 & CGGCCTTCCARRACACATCRMARG & Pyrocystis species & $440-470$ \\
\hline PyroR2 & GGCCTCYTBRAGCAAGACCTCA & & \\
\hline LpolyF1 & CTCCAAGGTCGCGCCCTTCAATTC & Lingulodinium polyedrum & 480 \\
\hline LpolyR1 & GACAAGCGCCTGGCAGAGCTG & & \\
\hline PreticF1 & CTCCTCAGTTGGGTTTCTGTG & Protoceratium reticulatum & 582 \\
\hline PreticR1 & CCTTCAACCGCCTTCTTGATGAAC & & \\
\hline
\end{tabular}

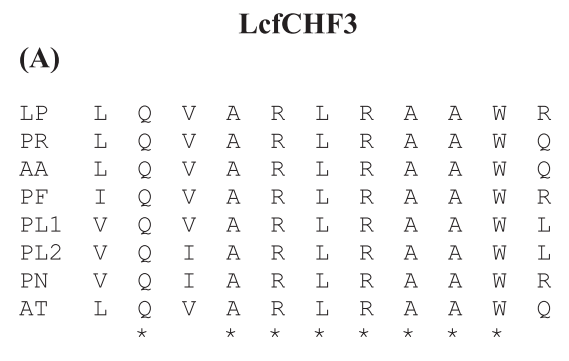

(B)

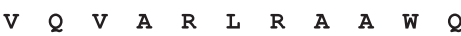

\section{LefCHR4}

$\begin{array}{lllllllllll}\mathrm{C} & \mathrm{K} & \mathrm{G} & \mathrm{F} & \mathrm{D} & \mathrm{Y} & \mathrm{G} & \mathrm{D} & \mathrm{K} & \mathrm{T} & \mathrm{L} \\ \mathrm{C} & \mathrm{K} & \mathrm{G} & \mathrm{F} & \mathrm{D} & \mathrm{Y} & \mathrm{G} & \mathrm{D} & \mathrm{K} & \mathrm{T} & \mathrm{L} \\ \mathrm{C} & \mathrm{K} & \mathrm{G} & \mathrm{F} & \mathrm{D} & \mathrm{Y} & \mathrm{G} & \mathrm{D} & \mathrm{K} & \mathrm{T} & \mathrm{L} \\ \mathrm{C} & \mathrm{K} & \mathrm{G} & \mathrm{F} & \mathrm{D} & \mathrm{Y} & \mathrm{G} & \mathrm{N} & \mathrm{K} & \mathrm{T} & \mathrm{L} \\ \mathrm{C} & \mathrm{K} & \mathrm{G} & \mathrm{F} & \mathrm{D} & \mathrm{Y} & \mathrm{G} & \mathrm{D} & \mathrm{K} & \mathrm{T} & \mathrm{L} \\ \mathrm{C} & \mathrm{K} & \mathrm{G} & \mathrm{F} & \mathrm{D} & \mathrm{Y} & \mathrm{G} & \mathrm{D} & \mathrm{K} & \mathrm{T} & \mathrm{L} \\ \mathrm{C} & \mathrm{K} & \mathrm{G} & \mathrm{F} & \mathrm{D} & \mathrm{Y} & \mathrm{G} & \mathrm{N} & \mathrm{K} & \mathrm{T} & \mathrm{L} \\ \mathrm{C} & \mathrm{K} & \mathrm{G} & \mathrm{F} & \mathrm{D} & \mathrm{Y} & \mathrm{G} & \mathrm{D} & \mathrm{K} & \mathrm{T} & \mathrm{L} \\ \star & \star & \star & \star & \star & \star & \star & & \star & \star & \star\end{array}$

$\begin{array}{lllllllllll}\text { C } & K & G & F & D & Y & G & N & K & T & L\end{array}$

(C)

TC CAG GTT GCA CGG CTT CGA gen gen tgg c acr tty cen AAA CTG ATG CCG CTG TTC TGG G

FIg. 2. Consensus-degenerate hybrid oligonucleotide primer (CODEHOP) PCR primers derived from the N-terminal region of the luciferase gene generated from the multiple sequence alignment of eight dinoflagellate luciferase sequences. (A) Multiple sequence alignment of the eight luciferase sequences created by BlockMaker. (B) The consensus amino acid sequence determined using the CODEHOP software. (C) The resulting nucleotide sequences for the primers, determined using the CODEHOP software, where the lowercase letters identify the $3^{\prime}$ degenerate region and the uppercase letters identify the $5^{\prime}$ consensus clamp.

L. polyedrum-specific and Protoceratium reticulatum (Clap. et J. Lachm.) Butschli-specific primer pairs (Table 1). Sample SL3 produced PCR products from the $P$. reticulatum-specific primers only, and samples SL4 and SL6 produced PCR products from the L. polyedrum-specific primers only. Sample SL5 was the only sample amplified using the universal primers that did not produce PCR products using any of the specific primer sets (Table 1).

Dinoflagellate luciferase sequences and phylogenetic analysis. PCR products amplified from all primer pairs and from both cultures and environmental samples were sequenced and checked for similarities with other sequences on GenBank. The sequences generated using the universal primer set were compared to the seven sequences present in GenBank and showed similarities at the nucleotide and amino acid levels. Sequence identities at the nucleotide level ranged from $37.3 \%$ to $100 \%$ across $\sim 480 \mathrm{bp}$. All the L. polyedrum strains, with the exception of L. polyedrum AF085332 and one sequence amplified from the English Channel, were identical. The average sequence identity among members of the
Alexandrium genus was $94.4 \%$. The two $P$. lunula strains were not identical, sharing a $96.4 \%$ sequence identity. The lowest nucleotide sequence identity of $37.3 \%$ was shared between Pyrocystis fusiformis (Willville-Thomson et Haeckel) F. F. Blackman and Alexandrium tamarense CCMP 1493. $G$ spinifera CCMP 409 shared the highest sequence identity with $P$. reticulatum CCMP 1889 of $91.5 \%$. Sequence identity at the amino acid level was similar to that of the nucleotide level, ranging from $37.7 \%$ to $100 \%$, with all the sequences generated in this study exhibiting the four conserved histidine residues as reported by Schultz et al. (2005) (Fig. 3).

The phylogenetic tree of the luciferase sequences, based on an alignment of approximately 160 amino acids, revealed five main clusters of the dinoflagellate luciferase sequences, a $L$. polyedrum clade (group L), Pyrocystis clade (group Py), Alexandrium clade (group A), G. spinifera clade (group G), and a $P$. reticulatum clade (Group Pr) (Fig. 4). These five groups are all supported by high bootstrap values. Within the Pyrocystis clade, the $P$. lunula strains 
cluster strongly together, with $P$. fusiformis and $P$. noctiluca J. Murray ex Haeckel forming an association, both supported by high bootstrap values. The Alexandrium luciferase sequences are grouped with $G$. spinifera and $P$. reticulatum but form two separate clades supported by high bootstraps. The strains A. cf. catenella and A. fundyense are identical, form- ing a monophyletic group. Interestingly, out of the A. tamarense luciferase gene sequences, only two cluster together, with the other strain, CCMP 1598, grouping with $A$. cf. catenella and A. fundyense. The luciferase sequences generated from the environmental samples clustered with either the $P$. reticulatum or the L. polyedrum clade.

LP_AF085332
Lp1738
Lp1933
Lp1936
LPMT16C4
LPM22
Ply1.1.7
SL4.1.2
SL5.1.5
Ply1.1.1
At1493
At115
Ac1911
Af1719
Af1978
A1909
A1910
At1598
Aa112
SL3.1.4
SL2.1.4
SL2.1.12
SL6.1.2
Pr1889
SL4.1.1
SL3.1.8
SL5.1.20
SL6.1.18
Gs409
P11131
P1_AAL40676
Pn-AAV35380
Pf AAV35379

LP AF085332

Lp 1738

Lp1933

Lp1936

LPMT16C 4

LpM22

Ply 1.1 .7

SL 4.1 .2

SL5.1.5

Ply1.1.1

At 1493

At 115

Ac1911

Af1719

Af 1978

A1909

A1910

At 1598

Aa 112

SL 3.1 .4

SL2.1. 4

SL2.1. 12

SL6.1.2

Pr1889

SL 4. 1.1

SL3.1.8

SL5. 1.20

SL6.1.18

Gs 409

P11131

PI AAL 40676

Pn AAV35380
Pf_AAV35379

RAAWRKAQGKPSAAVP--LQSAKPVAGSVVTATKDTGFCEKTGLESGGVAHGGALNAAQVAHLDEDAFKGGLHRPKFDSEGLHKPHTSGGKTYETGFH RAAWRKAQGKPSAAVP--LQSAKPVAGSVVTATKDTGFCEKTGLESGGVAHGGALNAAQVAHLDEDAFKGGLHRPKFDSEGLHKPHTSGGKTYETGFH RAAWRKAQGKPSAAVP--LQSAKPVAGSVVTATKDTGFCEKTGLESGGVAHGGALNAAQVAHLDEDAFKGGLHRPKFDSEGLHKPHTSGGKTYETGFH RAAWRKAQGKPSAAVP--LQSAKPVAGSVVTATKDTGFCEKTGLESGGVAHGGALNAAQVAHLDEDAFKGGLHRPKFDSEGLHKPHTSGGKTYETGFH RAAWRKAQGKPSAAVP--LQSAKPVAGSVVTATKDTGFCEKTGLESGGVAHGGALNAAQVAHLDEDAFKGGLHRPKFDSEGLHKPHTSGGKTYETGFH RAAWRKAOGKPSAAVP--LQSAKPVAGSVVTATKDTGFCEKTGLESGGVAHGGALNAAQVAHLDEDAFKGGLHRPKFDSEGLHKPHTSGGKTYETGFH RAAWRKAQGKPSAAVP--LQSAKPVAGSVVTATKDTGFCEKTGLESGGVAHGGALNAAQVAHLDEDAFKGGLHRPKFDSEGLHKPHTSGGKAYETGFH RAAWRKAQGKPSAAVP--LQSAKPVAGSVVTATKDTGFCEKTGLESGGVAHGGALNAAQVAHLDEDAFKGGLHRPKFDSEGLHKPHTSGGKTYETGFH RAAWRKAOGKPSAAVP--LOSAKPVAGSVVTATKDTGFCEKTGLESGGVAHGGALNAAOVAHLDEDAFKGGLHRPKFDSEGLHKPHTSGGKTYETGFH RAAWRKAQGKPSAAVP--LQSAKPVAGSVVTATKDTGFCEKTGLESGGVAHGGALNAAQVAHLDEDAFKGGLHRPKFDSEGLHKPHTSGGKTYETGFH RAAWQGAQQQMGAAPA--LKEAAPVAP----ADPQMGICEKTGLEAGGTSKGGTLNAAQVAHLGEGTEKDGLHKPKWDSEGLHKPHT I GGKTYETGFH RAAWQGAQQQMGAAPA--LKKAAPVAP----ADPQMGICEKTGLEAGGTSKGGALNAAQVAHLGEGTFKDGLHKPKWDSEGLHKPHTIGGKTYETGFH RAAWQGAQQQMGAAPV--PNKAAQPAP----AAPQVGICEKTGLEAGGTSKGGALNAAQVAHLGEGTFKDGLHKPKWDSEGLHKPHTIGGKTYDTGFH RAAWQGAQQQMGAAPV--PNKAAQPAP----AAPQVGICEKTGLEAGGTSKGGALNAAQVAHLGEGTFKDGLHKPKWDSEGLHKPHTIGGKTYDTGFH RAAWQGAQQQMGAAPV--PNKAAQPAP----AAPQVGICEKTGLEAGGTSKGGALNAAQVAHLGEGTFKDGLHKPKWDSEGLHKPHTIGGKTYDTGEH RAAWQGAQQQMGAAPV--PNKAAQPAP----AAPQVGICEKTGLEAGGTSKGGALNAAQVAHLGEGTFKDGLHKPKWDSEGLHKPHTIGGKTYDTGFH RAAWQGAQQQMGAAPV--PNKAAQPAP----AAPQVGICEKTGLEAGGTSKGGALNAAQVAHLGEGTFKDGLHKPKWDSEGLHKPHTIGGKTYDTGFH RAAWQGAQQKMGAAPV--LKKAAQLAP----AAPQVGICEKTGLEAGGTSEGGALNAAQVAHLGEGTFKDGLHKPKWDSEGLHKPHTIGGKTYDTGFH RAAWQRAQQQMGSAIV--PKKAAQPAA----ADPQVGICEKTGLEAGGTSKGGALNAAQVAHLGEGTFKDGLHKPKWDSEGLHKPHTIGGKTYETGFH RAAWQGAQQQTDAALE--PKKAAQSAP----AAPQLGFCEKTGLEAGGTSQGGALNAAQVAHLGEDAFKGGLHKPDWDKEGLHKPHTIGGKTYDTGFH RAAWQGAQQQTDAALE--PKKAAQSAP----AAPQLGFCEKTGLEAGGTSQGGALNAAQVAHLGEDAFKGGLHKPDWDKEGLHKPHTIGGKTYDTGFH RAAWQGAQQQTDAALE--PKKAAQSAP----AAPQLGFCEKTGLEAGGTSQGGALNAAQVAHLGEDAFKGGLHKPDWDKEGLHKPHTIGGKTYDTGFH RAAWQGAQQQTDAALE--PKKAAQSAP----AAPQLGFCEKTGLEAGGTSQGGALNAAQVAHLGEDAFKGGLHKPDWDKEGLHKPHTIGGKTYDTGFH RAAWQGAQQQTDAALE--PKKAAQSAP----AAPQLGFCEKTGLEAGGTSQGGALNAAQVAHLGEDAFKGGLHKPDWDKEGLHKPHTIGGKTYDTGFH RAAWQGAQQQTDAALE--PKKAAQSAP----AAPQLGFCEKTGLEAGGTSQGGALNAAQVAHLGEDAFKGGLHKPDWDKEGLHKPHT IGGKTYDTGFH RAAWQGAQQQTDAALE--PKKAARSAP----AAPQLGFCEKTGLEAGGTSQGGALNAAQVAHLGEDAFKGGLHKPDWDKEGLHKPHTIGGKTYDTGFH RAAWQGAQRQTDAALE--PKKAAQSAP----AAPQLGFCEKTGLEAGGTSQGGALNAAQVAHLGEDAFKGGLHKPDWDKEGLHKPHTIGGKTYDTGFH RAAWQGAQQQTGAALE--PKKAAQSAP----AAPQLGFCEKTGLEAGGTSQGGALNAAQVAHLGEDAFKGGLHKPDWDKEGLHKPHT IGGKTYDTGFH RAAWRRAQQQTGAALE--PTRAAQPAP----AVQSG-FCGKTGLEAGGTSQGGALNAAQVAHLGEDTFKGGLHKPKWDSDGLHKPHTIGGKTYDTGFH RAAWLSAQQSEGVPG-----ATAKAVPVAAKPVEQNGICEKTGLELSGTAKGGALSAAHVEHLDSEAFRDGLHQPKFHTDGLHMPHTSGEKTYETGFH RAAWLSAQQSEGVPG-----ATAKAVPVAAKPVEQNGICEKTGLELSGTAKGGALSAAHVEHLDSEAFREGLHQPKFHTDGLHMPHTSGEKTYETGFH RAAWRLAQD-------SSPLPVVAAKVAPPTEQSGLCEKTGLELSGTEKGGALSAAHVAHLDPEAFKGGLHKPNFHSEGLHMPHTSGGKEYETGFH RAAWRLVQDNKELSTIKESKALPEAAAETAPPTGQGALCEKTGLELGGTAQGGALSAAHVAHLDPDAFKGGLHKPNFHSEGLHMPHTSGDKTYDTGFH $\star \star \star \star$

YLLEAHELGGKNADGGFGGPLCADPFSPEIEOLCOALVREAODDKTLCFENFTKPCPOLTADPFSPEIEOLCOALVREAODDKTLCFENFTKPCPOLTKKOVEL YLLEAHELGGKNADGGFGGPLCADPFSPEIEQLCQALVREAQDDKTLCFENFTKPCPQLTADPFS PEIEQLCQALVREAQDDKTLCFENFTKPCPQLTKKQVEL YLLEAHELGGKNADGGFGGPLCADPFSPE IEQLCQALVREAQDDKTLCFENFTKPCPQLTADPFSPEIEQLCQALVREAQDDKTLCFENFTKPCPQLTKKQVEL YLLEAHELGGKNADGGFGGPLCADPFSPEIEQLCQALVREAQDDKTLCFENFTKPCPQLTADPFSPEIEQLCQALVREAQDDKTLCFENFTKPCPQLTKKQVEL YLLEAHELGGKNADGGFGGPLCADPFSPEIEQLCQALVREAODDKTLCFENFTKPCPQLTADPFSPEIEQLCQALVREAQDDKTLCFENFTKPCPQLTKKQVEL YLLEAHELGGKNADGGFGGPLCADPFSPEIEQLCQALVREAQDDKTLCFENFTKPCPQLTADPFSPEIEQLCQALVREAQDDKTLCFENFTKPCPQLTKKQVEL YLLEAHELGGKNADGGFGGPLCADPFSPEIEQLCQALVREAQDDKTLCFENFTKPCPQLTADPFSPEIEQLCQALVREAQDDKTLCFENFTKPCPQLTKKQVEL YLLEAHELGGKNADGGFGGPLCADPFSPEIEQLCQALVREAQDDKTLCFENFTKPCPQLTADPFS PEIEQLCQALVREAQDDKTLCFENFTKPCPQLTKKQVEL YLLEAHELGGKNADGGFGGPLCADPFSPEIEQLCQALVREAQDDKTLCFENFTKPCPQLTADPFSPEIEQLCQALVREAQDDKTLCFENFTKPCPQLTKKQVEL YLLEAHELGGKNADGGFGGPLCADPFS PEIEQLCQALVREAQDDKTLCFENFTKPCPQLTADPFSPEIEQLCQALVREAQDDKTLCFENFTKPCPQLTKKQVEL YLLEAHELGGKNADGGYGGHFCLDPYSKEISDLCTVLLSEAQQDKTLCYNNFTDPCPQLTLDPYSKEISDLCTVLLSEAQQDKTLCYNNFTDPCPQLTQRQVEL YLLEAHELGGKNADGGYGGPLCPDPYSKEISDLCTVLLSEAQQDKTLCYNNFTDPCPQLTPDPYSKEISDLCTVLLSEAQQDKTLCYNNETDPCPQLTQRQVEL YLLEAHELGGKSADGGYGGPLCPDPYSKEISGLCQVLLNEAQQDKTLCYNNFADPCPQLTPDPYSKE ISGLCQVLLNEAQQDKTLCYNNFADPCPQLTKQQVEL YLLEAHELGGKSADGGYGGPLCPDPYSKEISGLCOVLLNEAOODKTLCYNNFADPCPQLTPDPYSKEISGLCOVLLNEAOQDKTLCYNNFADPCPOLTKQOVEL YLLEAHELGGKSADGGYGGPLCPDPYSKEISGLCQVLLNEAQQDKTLCYNNFADPCPQLTPDPYSKEISGLCQVLLNEAQQDKTLCYNNFADPCPQLTKQQVEL YLLEAHELGGKSADGGYGGPLCPDPYSKEISGLCQVLLNEAQQDKTLCYNNFADPCPQLTPDPYSKEISGLCQVLLNEAQQDKTLCYNNFADPCPQLTKQQVEL YLLEAHELGGKSADGGYGGPLCPDPYSKEISGLCQVLLNEAQQDKTLCYNNFADPCPQLTPDPYSKEISGLCQVLLNEAQQDKTLCYNNFADPCPQLTKQQVEL YLLEAHELGGKNADGGYGGPLCPDPYSKEISDLCQVLLNEAQQDKTLCYNNFTDPCPQLTPDPYSKEISDLCQVLLNEAQQDKTLCYNNFTDPCPQLTKQQVDL YLLEAHELGGKNADGGYGGPLCADPYSQEITDLCQVLLNEAQQDKTLCYNNFTDPCPQLTADPYSQEITDLCQVLLNEAQQDKTLCYNNFTDPCPQLTKQQVEL YLLEAHDLGGKNKTGGYGGPLCADPYSQEISDLCQVLLDDAQQDKTLCYNNETDPCPQLTADPYSQEISDLCQVLLDDAQQDKTLCYNNFTDPCPQLTKRQVEL YLLEAHDLGGKNKTGGYGGPLCADPYSQEISDLCQVLLDEAQQDKTLCYNNFTDPCPQLTADPYSQEISDLCQVLLDEAQQDKTLCYNNFTDPCPQLTKRRVEL YLLEAHDLGGKNKTGGYGGPLCADPYSQEISDLCQVLLDEAQQDKTLCYNNFTDPCPQLTADPYSQEISDLCQVLLDEAQQDKTLCYNNFTDPCPQLTKRQVEL YLLEAHDLGGKNKTGGYGGPLCADPYSOEISDLCOVLLDEAOODKTLCYNNFTDPCPOLTADPYSOEISDLCOVLIDEAOODKTLCYNNFTDPCPOLTKROVEL YLLEAHDLGGKNKTGGYGGPLCADPYSQEISDLCQVLLDEAQQDKTLCYNNFTDPCPQLTADPYSQEISDLCQVLLDEAQQDKTLCYNNFTDPCPQLTKRQVEL YLLEAHDLGGKNKTGGYGGPLCADPYSQGISDLCQVLLDEAQQDKTLCYNNFTDPCPQLTADPYSQGISDLCQVLLDEAQQDKTLCYNNFTDPCPQLTKRQVEL YLLEAHDLGGKNKTGGYGGPLCADPYSQEISDLCQVLLDEAQQDKTLCYNNFTDPCPQLTADPYSQEISDLCQVLLDEAQQDKTLCYNNFTDPCPQLTKRQVEL YLLEAHDLGGKNKTGGYGGPLCADPYSREISDLCQVLLDEAQQDKTLCYNNFTDPCPQLTADPYSREISDLCQVLLDEAQQDKTLCYNNFTDPCPQLTKRQVEL YLLEAHDLGGKSKTGGYGGPLGADPYSQEISDLCQVLLDEAQQDKTLCYNNFTDPCPQLTADPYSQEISDLCQVLLDEAQQDKTLCYNNFTDPCPQLTKRQVEL YLLEAHELGGKNASGKYGGPLCADPYSQEISDLCQVLLSEAQQDKTLCYNNFTDPCPQLTADPYSQEISDLCQVLLSEAQQDKTLCYNNFTDPCPQLTKQQVEL YLLEVHDLGGKNKDGGFGGPLCSEPFSQKIADLAEVLLQEAQNDKTLAYTNFKDPAPTLTSEPFSQKIADLAEVLLQEAQNDKTLAYTNEKDPAPTLTKKQVEL YLLEVHDLGGKNKDGGFGGPLCSEPFSQEIADLAEVLLQEAQNDKTLAFTNERDPAPTLTSEPFSQEIADLAEVLLQEAQNDKTLAFTNFRDPAPTLTKKQVEL YLLEMHELGGKNKDGGFGGPLCQDPFSQKISHLCEVLLQEAQRDQTLAYSNFKAPCPMLTQDPFSQKISHLCEVLLQEAQRDQTLAYSNFKAPCPMLTKKQVDV YLLEMHELGGKNPDGGFGGPLCSDPFSDEIQSLSEVLLKEAQNDLTLAFNNEKDPCPMLTSDPFSDEIQSLSEVLLKEAQNDLTLAFNNEKDPCPMLTKKQVEL

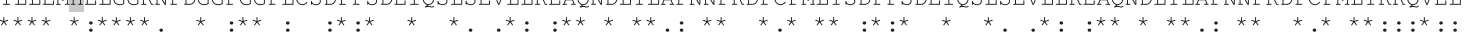

Fig. 3. Amino acid alignment of the luciferase sequences generated using the LcfCHF3/R4 primer pair. Asterisks indicate conserved amino acids, and highlighted amino acids indicate the conserved histidine residues. 


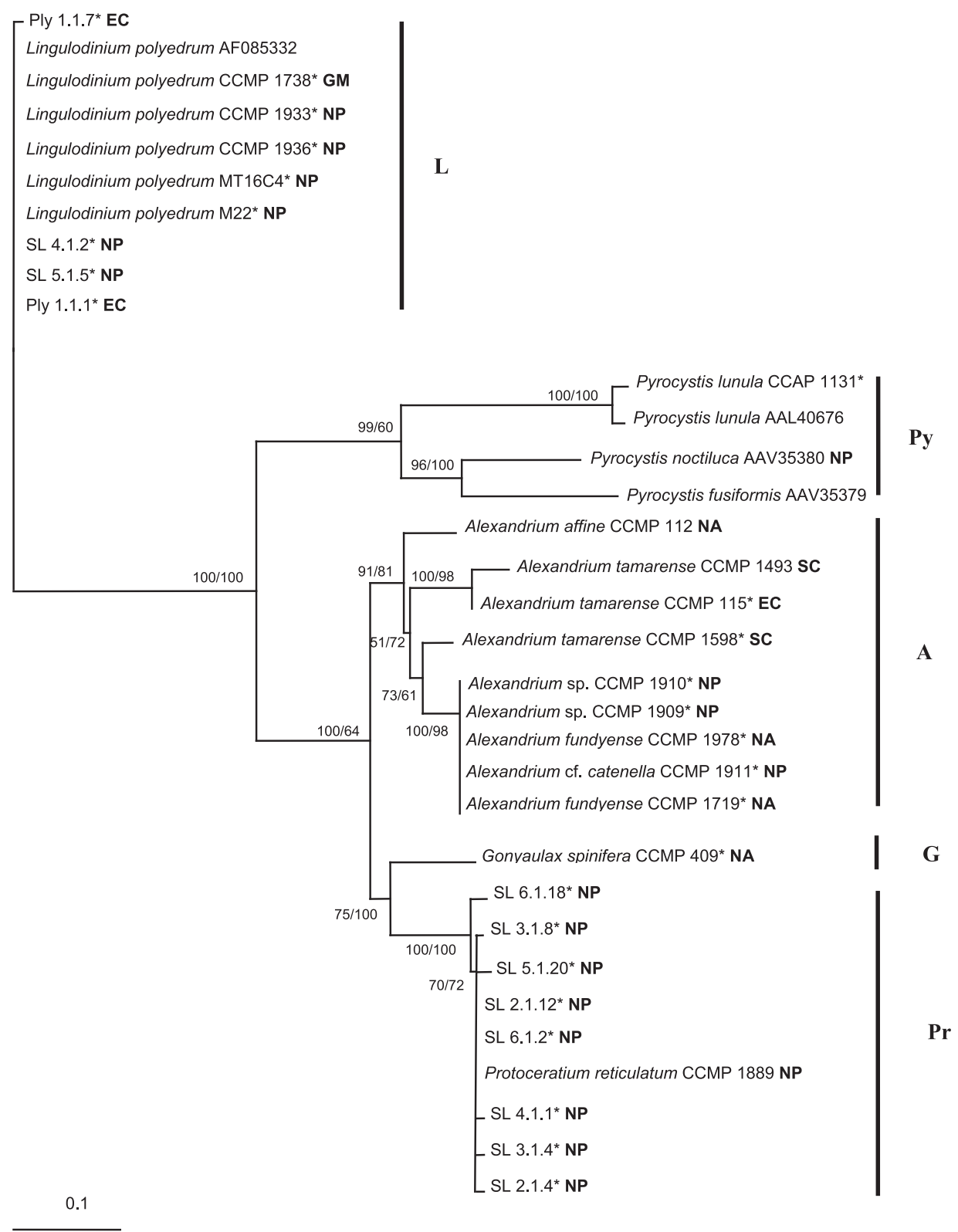

FIG. 4. Unrooted neighbor-joining tree based on an amino acid alignment of partial sequences of the N-terminal region and beginning of the first domain of the luciferase gene using a distance algorithm between luciferase sequences generated in this study and other dinoflagellate sequences from GenBank (Neighbor, in PHYLIP version 3.66). Bootstrap values were retrieved from 100 replicates and are indicated at the nodes (distance matrix and parsimony, respectively). The distance between two strains is acquired by adding the lengths of the connecting branches, using the scale, which depicts one amino acid substitution per 10 amino acid residues. Accession numbers are detailed in Tables 1 and 2. Asterisks denote the sequences amplified through the course of this study, and letters indicate the geographic origin (where known), where EC is English Channel, GM is Gulf of Mexico, NP is North Pacific, NA is North Atlantic, and SC is South China Sea. The five phylogenetic clades are indicated as L, Lingulodinium; Py, Pyrocystis; A, Alexandrium; G, Gonyaulax; and Pr, Protoceratium.

\section{DISCUSSION}

The universal primer set developed in this study shows convincing evidence of being highly specific to dinoflagellates that produce bioluminescence. The region selected for primer design was based on the homology previously reported within the three domains of the luciferase gene (Liu et al. 2004).
Nucleotide similarities within the three domains of the luciferase gene meant that any primers designed within these domains increased the probability of amplification of multiple targets, hence yielding mixed PCR products. Consequently, the region selected was located within the nonhomologous (to the other domains) N-terminal region of the luciferase gene and the beginning of the first 
domain of the luciferase gene. The CODEHOP software identified several primer pairs, which were tested accordingly, with the CHF3/R4 set yielding optimal results (data not shown). The positive result for all the known bioluminescent strains (Table S1), along with the detection of luciferase in G. spinifera CCMP 409, a low-light-emitting dinoflagellate, highlights the usefulness of the CODEHOP strategy in amplifying distantly related gene sequences. This result also leads to speculation that there may be many other unidentified bioluminescent dinoflagellates that could be tested using these molecular primers. Palmer and Colwell (1991) discovered similar findings in their study of the bacterium Vibrio cholera, where strains not found to be visibly bioluminescent did indeed produce low levels of light. In addition, they reported the presence of bacterial luciferase in strains of $V$. cholera that do not emit any light at all, suggesting that this may also be true in the dinoflagellates. It may also be possible that dinoflagellates that were previously bioluminescent, early in evolutionary history, may possess remnants of luciferase genes or luciferase that is not expressed.

The CODEHOP primer set also amplified luciferase sequences from environmental samples. Positive samples were identified from a sample collected from the English Channel, Plymouth, UK, and also samples collected from San Luis Obispo Bay, California, USA (Table 1), with the sample collected from the English Channel not being tested for bioluminescence. This finding again emphasizes the application of using these primers on natural water samples to confirm the presence of potentially low levels of these light-emitting organisms, or where bioluminescent organisms have not been detected at the time of sampling. The samples from California were collected in an area known to frequently display bioluminescence and where bioluminescence was observed at the time of the sample collection. In these waters, bioluminescence was highly variable due to changes in the water column (Fig. 1). Interestingly, the samples collected when bioluminescence was the greatest-SL8, SL9, and SL10-did not yield PCR products using the primers developed in this study (Table 1). This finding possibly suggests that other organisms in the water column, such as bacteria, were responsible for the bioluminescence detected. It is envisaged that future long-term studies will produce a more detailed picture of the bioluminescent dinoflagellate community, combined with the concurrent data on the biogeochemistry and bioluminescence of the water column. The acquisition of the PCR products from the environment allowed for the generation of more new putative dinoflagellate luciferase sequences, such as sequences SL6.1.18 and SL5.1.20, which could potentially represent new bioluminescent dinoflagellate species.

The genus/species-specific primer sets developed proved to be specific to the different dinoflagellate taxonomic entities that these primers were designed for, providing a tool to search for specific bioluminescent groups (Table S1). The primer sets were also tested on the environmental samples collected, with no amplification from the Alexandrium- and Pyrocystis-specific primer pairs, suggesting that these species were absent. However, the presence of $L$. polyedrum and $P$. reticulatum-like strains was confirmed by the generation of PCR products using the specific primer pairs. Identical $P$. reticulatum sequences and $L$. polyedrum sequences were also amplified from the environmental samples, confirming the presence of these organisms in the samples collected. Interestingly, sample SL5 was positive for luciferase with the universal primer set and had highly similar sequences to L. polyedrum, yet did not amplify PCR product with the $L$. polyedrum-specific primer pair. This finding could potentially suggest that the sequences from these samples are in fact from a different species. Likewise, in SL4, a product is amplified by the universal primers where the sequence is highly similar to the $P$. reticulatum sequence; however, the species-specific primers do not amplify from this sample. The testing of the primers on environmental samples has indicated a dynamic community within the Californian waters, since some of the samples collected on the same day, but at a different depth, were positive for different dinoflagellate species. These results demonstrate the potential for the specific primers to detect the presence of particular dinoflagellates, without the requirement of morphological identification.

Novel luciferase sequences were discovered, with the sequence of G. spinifera CCMP 409, the lowlight-emitting dinoflagellate, sharing a high sequence identity with $P$. reticulatum and also showing the tendency to cluster with this strain in the phylogenetic analysis (Fig. 4). The L. polyedrum luciferase sequences were all identical with respect to the amino acid sequence, except for one UK strain (which differed by only one residue). This observation suggests low intraspecific diversity of this gene, particularly among strains of $L$. polyedrum originating from North Atlantic and Pacific waters. This high sequence conservation was not replicated among the two $P$. lunula strains, with 17 nucleotide changes detected, equating to four amino acid substitutions. However, it is not known whether these strains originated from different waters.

The sequences from the Alexandrium genus exhibit strong homology, forming a definite monophyletic group, with five of the luciferase sequences generated being identical, including $A$. fundyense CCMP 1978, A. fundyense CCMP 1719, Alexandrium CCMP 1909, Alexandrium CCMP 1910, and A. cf. catenella CCMP 1911 (Fig. 4). This high sequence conservation is not entirely surprising among this group, considering that A. tamarense, A. catenella, and $A$. fundyense are highly similar at both the 
morphological and molecular levels. It has been documented, from phylogenetic analyses of these strains based on 18S rRNA (Scholin 1998) and the LSU D1-D2 rRNA regions (Persich et al. 2006), that these species tend to group with respect to where they originate geographically. To an extent, the luciferase phylogeny supports this trend, with the aforementioned identical strains-A. fundyense 1719 and 1978, Alexandrium 1909 and 1910, and also A. cf. catenella 1911-all originating from North American waters, which is one of the oceanographic regions previously identified as a geographic genetically unique clade of Alexandrium (Scholin et al. 1994). The sequences and phylogenetic clustering of A. tamarense do not, however, relate to their geographic origin (Fig. 4). This is intriguing as A. tamarense CCMP 1493 and A. tamarense CCMP 115 strongly associated with each other, yet $A$. tamarense CCMP 1598 preferentially clustered with the $A$. cf. catenella/A. fundyense group (Fig. 4). It was initially hypothesized that the geographic origin of these strains was the underlying factor accounting for this clustering; however, strains CCMP 1493 and 1598 actually both originated from West Hong Kong Island, China, whereas CCMP 115 was isolated from Plymouth, UK. To be consistent with the Alexandrium species complex geographic separation theories, one possible explanation for the West Hong Kong Island groupings is the introduction of nonnative dinoflagellate species into other areas, such as via ship ballast water, in the form of resting cysts (Hallegraeff and Bolch 1992). This possibility would potentially account for the high similarity observed between the Plymouth A. tamarense strain and the Hong Kong Island strain CCMP 1493, despite the geographic separation. It may, however, be that some alternative selective pressure has caused the A. tamarense CCMP 115 and 1493 to diverge from others of the A. tamarense species complex sequences analyzed here. A. affine (H. Inouye et Fukuyo) Balech clustered away from the other Alexandrium species, inferred by high bootstrap values, suggesting that this luciferase may have diverged from the others and has a unique luciferase sequence.

The data generated in this study have extended our knowledge of dinoflagellate luciferases and demonstrated that luciferase is conserved across at least five genera and 10 species and is even conserved in low-light-emitting dinoflagellates, such as G. spinifera. We present molecular tools for assessing the presence of bioluminescent dinoflagellates using universal and species-specific luciferase primers with applications for the study of bioluminescence in the natural environment. Although bioluminescent dinoflagellate blooms are often clearly visible in the water column, lower cell densities or strains that emit low light have the potential to go unreported. By having a universal primer set, one can rapidly create a profile of the bioluminescent dinoflagellate community, which is important to assess the population dynamics of dinoflagellates and to diagnose and predict bioluminescence in the water column. We have shown that the dinoflagellate luciferase sequences are conserved; however, they are variable enough for one to discriminate the taxonomy of the bioluminescent dinoflagellates at the genus level. An amalgamation of this PCR with other molecular techniques, such as terminal restriction fragment length polymorphism (T-RFLP) or denaturing gradient gel electrophoresis (DGGE) could also be utilized to study natural communities to obtain further information regarding the bioluminescent dinoflagellates and community dynamics.

We thank Dr. Tim Rose (University of Washington, USA) for his assistance in the design of the CODEHOP primers. This research was supported by the office of naval research (ONR award number N000140410180, awarded to D. I. R., and N000140510341, awarded to M. A. M.).

Abrahams, M. V. \& Townsend, L. D. 1993. Bioluminescence in dinoflagellates: a test of the burglar alarm hypothesis. Ecology 74:258-60.

Akimoto, H., Wu, C., Kinumi, T. \& Ohmiva, Y. 2004. Biological rhythmicity in expressed proteins of the marine dinoflagellate, L. polyedrum, demonstrated by chronological proteomics. Biochem. Biophys. Res. Commun. 315:306-12.

Altschul, S. F., Gish, W., Miller, W., Myers, E. W. \& Lipman, D. J. 1990. Basic local alignment search tool. J. Mol. Biol. 215:403-10.

Burkenroad, M. D. 1943. A possible function of bioluminescence. J. Mar. Sci. 5:161-4.

DeSa, R. \& Hastings, J. W. 1968. The characterisation of scintillons. Bioluminescent particles from the marine dinoflagellate Gonyaulax polyedra. J. Gen. Physiol. 51:105-23.

Doyle, J. J. \& Doyle, J. L. 1990. Isolation of plant DNA from fresh tissue. Focus 12:13-5

Eckert, R. \& Reynolds, G. T. 1967. The subcellular origin of bioluminescence in Noctiluca miliaris. J. Gen. Physiol. 50:1429-59.

Esaias, W. E. \& Curl, H. C. 1972. Effect of dinoflagellate bioluminescence on copepod ingestion rates. Limnol. Oceanogr. 17:901-6.

Felsenstein, J. 1993. PHYLIP (Phylogeny Inference Package). Distributed by the author. Department of Genetics, University of Washington, Seattle.

Fleisher, K. J. \& Case, J. F. 1995. Cephalopod predation facilitated by dinoflagellate luminescence. Biol. Bull. 189:263-71.

Fogel, M. \& Hastings, J. W. 1972. Bioluminescence: mechanism and mode of control of scintillons activity. Proc. Natl. Acad. Sci. U. S. A. 69:690-3.

Fritz, L., Morse, D. \& Hastings, J. W. 1990. The circadian bioluminescence rhythm of Gonyaulax is related to daily variations in the number of light-emitting organelles. J. Cell Sci. 95:321-8.

Goddard, V. J., Baker, A. C., Davy, J. E., Adams, D. G., De Ville, M. M., Thackeray, S. J., Maberley, S. C. \& Wilson, W. H. 2005. Temporal distribution of viruses, bacteria and phytoplankton throughout the water column in a freshwater hypereutrophic lake. Aquat. Microb. Ecol. 39:211-23.

Gomez, F. 2005. A list of free-living dinoflagellate species in the world's oceans. Acta Bot. Croat. 64:129-212.

Guillard, R. R. L. \& Ryther, J. H. 1962. Studies of marine planktonic diatoms. I. Cyclotella nana Hustedt and Detonula confervacea Cleve. Can. J. Microbiol. 8:229-39.

Hackett, J. D., Anderson, D. M., Erdner, D. L. \& Bhattacharya, D. 2004. Dinoflagellates: a remarkable evolutionary experiment. Am. J. Bot. 91:1523-34.

Hallegraeff, G. M. \& Bolch, C. J. 1992. Transport of diatom and dinoflagellate resting spores in ships ballast water: implications for plankton biogeography and aquaculture. J. Plankton Res. 14:1067-84.

Hastings, J. W. 1989. Chemistry, clones and circadian control, of the dinoflagellate bioluminescent system. J. Biolum. Chemilum. 4:12-9.

Hastings, J. W. 1996. Chemistries and colours of bioluminescent reactions: a review. Gene 173:5-11.

Herren, C. M., Haddock, S. H. D., Johnson, C., Orrico, C. M., Moline, M. A. \& Case, J. F. 2005. A multi-platform bathyphotometer for fine-scale, coastal bioluminescence research. Limnol. Oceanogr. Methods 3:247-62. 
Knaust, R., Urbig, T., Li, L., Taylor, W. \& Hastings, J. W. 1998. The circadian rhythm of bioluminescence in Pyrocystis is not due to differences in the amount of luciferase: a comparative study of three bioluminescent marine dinoflagellates. J. Phycol. 34:167-72.

Liu, L., Wilson, T. \& Hastings, J. W. 2004. Molecular evolution of dinoflagellate luciferases, enzymes with three catalytic domains in a single polypeptide. Proc. Natl. Acad. Sci. U. S. A. 101:16555-60.

Okamoto, O. K., Liu, L., Robertson, D. L. \& Hastings, J. W. 2001. Members of a dinoflagellate luciferase gene family differ in synonymous substitution rates. Biochemistry 40:15862-8.

Page, R. D. M. 1996. TREEVIEW: an application to display phylogenetic trees on personal computers. Comput. Appl. Biosci. 12:357-8.

Palmer, L. M. \& Colwell, R. R. 1991. Detection of luciferase gene sequences in non-bioluminescent Vibrio cholera by colony hybridisation and polymerase chain reaction. Appl. Environ. Microbiol. 57:1286-93.

Persich, G. R., Kulis, D. M., Lilly, E. L., Anderson, D. M. \& Garcia, V. M. T. 2006. Probable origin and toxin profile of Alexandrium tamarense Balech from Southern Brazil. Harmful Algae 5:36-44.

Poupin, J., Cussatlegras, A. \& Geistdoerfer, P. 1999. Plancton marin bioluminescent. Rapport Scientifique du loen, Brest, France, 64 pp.

Rose, T. M., Schultz, E. R., Henikoff, J. G., Pietrokovski, S., McCallum, C. M. \& Henikoff, S. 1998. Consensus-degenerate hybrid oligonucleotide primers for amplification of distantly related sequences. Nucleic Acids Res. 26:1628-35.

Schmitter, R. E., Njus, D., Sulzman, F. M., Gooch, V. D \& Hastings, J. W. 1975. Dinoflagellate bioluminescence. A comparative study of in vitro components. J. Cell. Physiol. 87:123-34.

Scholin, C. A. 1998. Morphological, genetic and biogeographic relationships of the toxic dinoflagellates Alexandrium tamarense, A. catenella and A. fundyense. In Anderson, A. D. \& Hallegraeff, G. M. [Eds.] Physical Ecology of Harmful Algal Blooms. Springer-Verlag, Heidelberg, Germany, pp. 13-27.

Scholin, C. A., Herzog, M., Sogin, M. \& Anderson, D. M. 1994. Identification of group- and strain-specific genetic markers for globally distributed Alexandrium (Dinophyceae). II. Sequence analysis of a fragment of the LSU rRNA gene. J. Phycol. 30:999-1011.
Schultz, L. W., Liu, L., Cegielski, M. \& Hastings, J. W. 2005. Crystal structure of a pH-regulated luciferase catalysing the bioluminescence oxidation of an open tetrapyrole. Proc. Natl. Acad. Sci. U. S. A. 102:1378-83.

Sweeney, B. M. 1987. Bioluminescence and circadian rhythms. In Taylor, F. J. R. [Ed.] The Biology of Dinoflagellates. Blackwell Scientific Publications, Oxford, UK, pp. 269-81.

Thompson, J. D., Higgins, D. G. \& Gibson, T. J. 1994. CLUSTALW: improving the sensitivity of progressive multiple sequence alignment through sequence weighting, position specific gap penalties and weight matrix choice. Nucleic Acids Res. 22:4673-80. 